\title{
A New Approach to Multidisciplinary Design Optimization of Solid Propulsion System Including Heat Transfer and Ablative Cooling
}

\author{
Amirhossein Adami ${ }^{1}$, Mahdi Mortazavi², Mehran Nosratollahi
}

\begin{abstract}
The optimum design of a solid propulsion system consists of optimization of various disciplines including structure, aerothermodynamics, heat transfer, and grain geometry. In this paper, an efficient model of every discipline has been developed, and a suitable framework is introduced for these hard-coupled disciplines. Hybrid optimization algorithm is used to find the global optimum point including genetic algorithm and sequential quadratic programing. To show the performance of the proposed algorithm, the required correction factor values have been carefully derived using comparison between more than 10 real solid propulsion systems and the proposed algorithm results. According to the results, the derived correction factors are close to 1, with scattering level better than 0.97. In addition, it is shown that the proposed algorithm (errors $<8 \%$ ) is more accurate in comparison with the conventional approach (errors < 17\%). Then, for a case study, multidisciplinary analysis has been done based on 3 general objectives including dry mass, total mass, and specific impulse. It means that the optimum specific impulse is not the maximum value and the optimum dry mass is not the minimum value. Finally, the proposed algorithm can be used to directly derive the optimum configuration for every mission requirement.
\end{abstract}

KEYWORDS: Multidisciplinary design, Hybrid optimization, Heat transfer, Solid propulsion, Ablation.

\section{INTRODUCTION}

Solid thrusters are widely used in space applications, especially in orbital maneuvers and launch vehicles, and solid boosters are the most important part of space transportation mission. Heavy launch vehicles use solid boosters as semi first stage, and upper stages use solid thruster to reach destination orbit. Reentry vehicles need to deorbit with high amount of impulse in short time, therefore, they use solid propellant propulsion (Adami 2015). Interests grow up because of higher safety and lower required dynamic parts. These applications of solid propulsion thrusters lead to the development of a renewed interest in optimum designing methods. Conventional design methods are involved in subsystems optimization, but a local optimum solution can be found. For example, in view of propulsion discipline, higher specific impulse (Isp) is considered as a better propulsion, while lower structure mass is better in view of structure discipline. Total mass is a reasonable estimation of cost, which includes Isp and structure mass (thermal protection materials, nozzle, and combustion chamber mass). Optimization of each part conflicts with the others. For example, increase in pressure of combustion chamber increases the Isp (lower required propellant mass), while more structure thicknesses are needed. Thus, designing variables should be optimized according to the system level. To do this, solid propulsion system is broken down into 4 major subsystems including combustion chamber, divergentconvergent (D-C) nozzle, solid propellant grain, and thermal protection system (TPS). The mass modeling of each subsystem

\footnotetext{
三 1.Maleke Ashtar University of Technology - Aerospace Department - Tehran - Iran. 2.University of Isfahan - Faculty of Engineering - Esfahan - Iran. Author for correspondence: Amirhossein Adami | Maleke Ashtar University of Technology - Aerospace Department | Babae Highway, Lavizan | $1774-15875$ - Tehran - Iran | Email: adami_amir@mut.ac.ir

Received:June 10, 2016 | Accepted: Sep. 18, 2016
} 
is introduced based on aerothermodynamics, structure, heat transfer, and materials.

Single discipline optimization is more attractive, especially for internal ballistic performance optimization (Hainline 2006) or grain optimization including geometry (Nisar and Guozhu 2008; Nisar et al. 2008) and burn-back simulation (Püskülcü 2004; Yildirim 2007). Albarado et al. (2012) used a particle swarm/pattern search hybrid optimizer to drive an optimum solid rocket motor by concentrating on grain optimization including wagon wheels, dog bones, stars, and multiple tapered sections. Konečný et al. (2007) proposed a traditional method of design that serves for a more accurate determination of the ballistic, weight, and geometric characteristics of the solid propellant rocket motor for the given tactical and technical requirements. In Acik (2010), an optimization tool for internal ballistic design of solid rocket motors was developed using a direct search algorithm. Multidisciplinary design and optimization strategy for the conceptual design of a multistage ground-based interceptor have been carried out in Zeeshan et al. (2010) using genetic algorithm (GA) and sequential quadratic programing (SQP) to minimize the total mass. In Roshanian and Keshavarz (2006), multidisciplinary design optimization was applied to a sounding rocket using response surface methods. In Jodei et al. (2009), multidisciplinary design optimization of a small solid propellant launch vehicle was introduced using system sensitivity analysis.

According to the mentioned references, numerous methods have been developed for optimization of solid thrusters. All of the proposed methods focus on propulsion model simplification because of the increase in design variable parameters. Grain geometry and internal ballistic optimizations are 2 favorite examples of trying to have an optimum configuration, but, as mentioned before, optimizing in 1 discipline does not guarantee a global optimum point. In addition, heat transfer from combustion chamber has not been considered in the aforementioned studies, and empirical correction factor (applied in adiabatic temperature) has been usually adopted. In this paper, a new approach of multidisciplinary design optimization will be introduced considering internal ballistic performance, grain geometry, structure mass, nozzle geometry, insulator, and heat transfer. Hybrid optimization algorithm (GA-SQP) is used to find the global optimum point in shorter elapsed time based on minimizing the total mass of solid propulsion system or maximizing Isp.

\section{SOLID PROPELLANT THRUSTER}

Generally, the motor case is a cylindrical cover containing solid propellant, igniter, and insulator. The combustion takes place in the motor case; therefore, sometimes, it is referred to as combustion chamber. The schematic diagram of a solid propellant thruster is shown in Fig. 1.

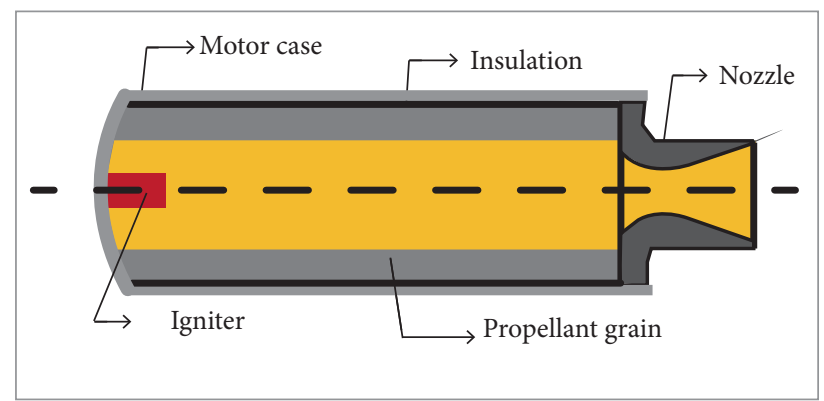

Figure 1. Subsystem of solid propellant thruster.

The case must be capable of withstanding the internal pressure resulting from the motor operation, approximately 3 - $30 \mathrm{MPa}$, with a sufficient safety factor. Therefore, motor case is usually made either from metal (high-resistance steels or high-strength aluminum alloys) or composite materials (glass, $\operatorname{Kevlar}{ }^{\circledR}$, carbon). Besides the stresses due to the pressure in the chamber, thermal stresses may sometimes be critical and, when the case also serves as flight vehicle body, bending loads and inertial forces play an important role in determining the thickness and the material of the motor case as well.

The ignition system gives the necessary energy to the propellant surface to initiate combustion. Ignition usually starts with an electrical signal and has a high specific energy, being designed to release either gases or solid particles. Conventional heat releasing compounds are usually pyrotechnic materials, black powder, metal-oxidant formulations, and conventional solid rocket propellant.

High temperature of the combustion gases, ranging from approximately 2,000 to $3,800 \mathrm{~K}$, requires the protection of the motor case or other structural subcomponents of the rocket motor. Typical insulator materials have low thermal conductivity and high heat capacity, being usually capable of ablative cooling. Most commonly used insulation materials are ethylene propylene diene monomer (EPDM) with addition of reinforcing materials.

High-temperature and high-pressure combustion gases are discharged through the D-C nozzle. By this way, chemical energy 
of the propellant is converted to the kinetic one, and thrust is obtained. The geometry of the nozzle directly determines how much of the total energy is converted to kinetic energy. Therefore, nozzle design has a very important role in the performance of a rocket motor.

Solid propellant is cast in certain configuration and geometry called propellant grain. The propellant grains can be sub-categorized into 2 main configurations: case-bonded and freestanding. Case-bonded grains are directly cast into the motor case already provided with thermal insulation.

The mentioned parts of solid propellant thruster should be modeled and optimized to have an optimum solution, but some of them have lower effect on cost function (mass) such as igniter and insulator. Therefore, these disciplines could be omitted in conceptual phases. On the other hand, although lower effect on cost function is negligible, strong effect on constrains is critical. Insulator and heat transfer are the examples of such disciplines.

\section{INTERNAL BALLISTIC MODELING}

Thrust value and Isp introduce the thruster size and performance. The mentioned parameters can be calculated by Eq. 1:

$$
\begin{aligned}
& T_{v a c}=\frac{A^{*} P_{e}\left(\gamma M_{e}^{2}+1\right)}{M_{e}^{2}}\left[\frac{2}{\gamma+1}\left(1+\frac{\gamma-1}{2} M_{e}^{2}\right)\right]^{\frac{\gamma+1}{2(\gamma-1)}} \\
& I s p_{v a c}=\frac{T_{v a c}}{\dot{m} g_{0}}
\end{aligned}
$$

where: $T_{v a c}$ is the vacuum thrust; $A^{*}$ is the throat area; $P_{e}$ is the exit pressure; $M_{e}$ is the Mach number at the exit section of the nozzle; $\gamma$ is the isentropic exponent; $\dot{m}$ is the mass flow; Isp $_{v a c}$ is the vacuum specific impulse.

Well-known relations of mass flow are introduced by Eq. 2:

$$
\begin{aligned}
& \dot{m}_{\text {out }}=\rho_{e} A_{e} v_{e} \\
& \dot{m}_{\text {in }}=\rho_{\text {propellant }} A_{\text {burn }} v_{\text {burn }} \\
& \Delta \dot{m}=\dot{m}_{\text {in }}-\dot{m}_{\text {out }} \\
& \dot{P}_{c}=\frac{\Delta \dot{m} R T_{c}-P_{c} \dot{V}_{\text {Comb }}}{V_{\text {Comb }}}
\end{aligned}
$$

where: $v_{b u r n}$ is the burning rate; $A_{e}$ is the exit area; $v_{e}$ is the exit velocity of flow; $\rho_{e}$ is the exit density; $R$ is the constant parameter of gas; $\rho_{\text {propellant }}$ is the density of the propellant; $A_{\text {burn }}$ is the burning area; $T_{c}$ is the combustion chamber temperature; $P_{c}$ is the combustion chamber pressure; $V_{\text {Comb }}$ is the combustion volume.

The relation between burning rate and chamber pressure is governed by the empirical Eq. 3, also known as Saint Robert's burn rate law:

$$
v_{\text {bum }}=a P_{c}^{n}
$$

This empirical expression defines the burning rate of the propellant. Values of $a$ and $n$ are usually derived from strand burner tests or small sub-scale burning rate test motor firings at different operating pressures. Accurate relation for burn rate is derived by solving the energy equations at burning surface of the grain. Burning rate is function of combustion pressure, initial temperature, combustion temperature, and velocity of hot gases. If heat transfer is considered, then accurate relation of burning rate can be predicted. Supplementary required equations can be found in Adami (2015), Acik (2010), and Hainline (2006). Flow data of the internal ballistic discipline is illustrated in Fig. 2.

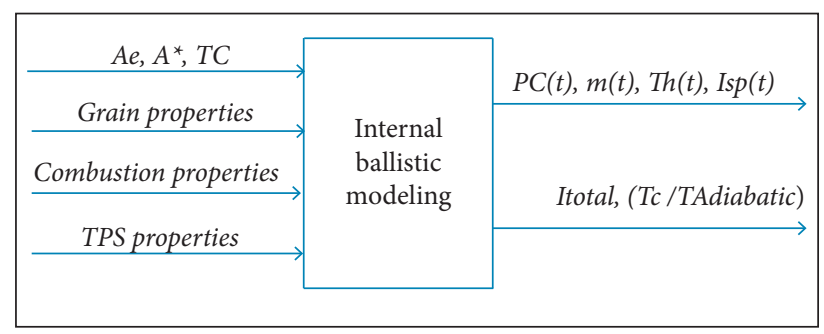

Figure 2. Internal ballistic modeling and input-output diagram.

\section{NOZZLE MODELING}

The high pressure and temperature flow exits from the combustion chamber and enters the D-C nozzle, which changes the potential to the kinetic energy. Nozzles are usually classified according to their structural mounting technique or shape of the contour, such as submerged, movable, and bell-shaped nozzle. Conical nozzle can be selected for conceptual design phase. Divergence half angle of cone, chamber diameter, throat diameter, convergence half angle of cone, and exit diameter determine the nozzle geometry. The geometry parameters of a 
nozzle are shown in Fig. 3 and correlate with the thermodynamic ones. Equation 4 presents the relation between geometry and thermodynamic parameters:

$$
\begin{aligned}
& \theta_{1}=45 \quad, \quad \theta_{2}=15 \\
& A^{*}=\frac{\dot{m} \sqrt{\frac{T_{c} R}{\gamma}}}{P_{c}}\left(1+\frac{\gamma-1}{2}\right)^{\frac{\gamma+1}{2(\gamma-1)}} \\
& A_{e}=\frac{A^{*}}{M_{e}}\left[\frac{2}{\gamma+1}\left(1+\frac{\gamma-1}{2} M_{e}^{2}\right)\right]^{\frac{\gamma+1}{2(\gamma-1)}}=A^{*} Z_{\text {exponsion }} \\
& L_{\text {con }}=\frac{R_{c}-R^{*}}{\tan \theta_{1}}, \quad L_{\text {div }}=\frac{R_{e}-R^{*}}{\tan \theta_{2}} \\
& \text { Thrust }_{\text {real }}=\lambda_{1} \text { Thrust } \\
& \lambda_{1}=\frac{1+\cos \left(\theta_{2}\right)}{2}=0.97
\end{aligned}
$$

where: $\lambda_{1}$ is the nozzle correction factor (conical); $Z_{\text {expansion }}$ is the expansion ratio (area); $R^{*}$ is the throat radius; $R_{c}$ is the combustion chamber radius; $R_{e}$ is the exit section radius; $\theta_{1}$ is the half angle of convergent part; $\theta_{2}$ is the half angle of divergent part; $L_{c o n}$ is the convergent length of the nozzle; $L_{d i v}$ is the divergent length of the nozzle.

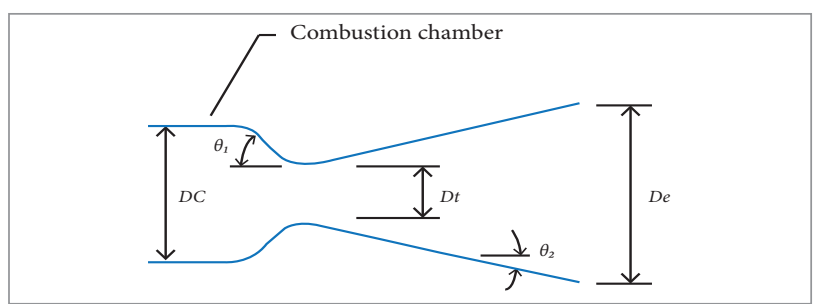

Figure 3. Nozzle geometric parameters.

Combustion product gases have an erosive effect with their high temperature, high velocity, and with a high concentration of liquid and solid particles like metal oxides inside them. The material selection of the nozzle is a very important step of nozzle design, especially for the throat region, where erosive effects are more dominant. Refractory metal, carbon-containing composites or graphite, and reinforced plastic that will withstand erosive effects are commonly used as throat material. Flow data of the nozzle discipline is illustrated in Fig. 4.

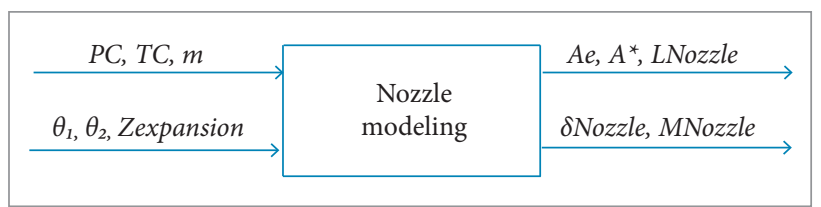

Figure 4. Nozzle modeling and input-output diagram.

\section{GRAIN GEOMETRY MODELING AND BURN-BACK ANALYSIS}

Burning surface changes during motor operation. Burnback analysis determines these changes in the grain geometry. The geometric design of the grain ultimately defines the performance characteristics that can be obtained with given propellant type and nozzle. Numerous tools and algorithms (analytical, numerical, and drafting) are developed to analyze the various grain models. Different thrust-time profiles are required for different missions such as progressive, neutral or boost, and sustain. Different thrust time profiles can be obtained by changing the propellant grain configuration, which can be categorized as end-burning grain, internal-burning tube, external-burning tube star, slot and combined configuration (for example, finocyl geometry). Figure 5 shows some of the grain configurations.

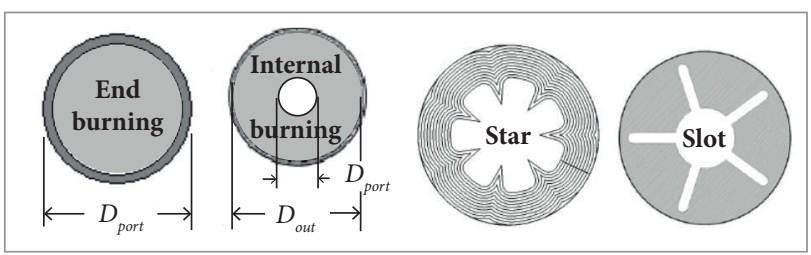

Figure 5. Grain configurations.

Each grain configuration has specific design variables. End-burning configuration needs 2 design variables, star grains need 8 independent design variables, and slot grains need 6 design variables. In this paper, available designing and analyzing codes are used, which have been verified before. For example, design variables of star grain are introduced in Fig. 6.

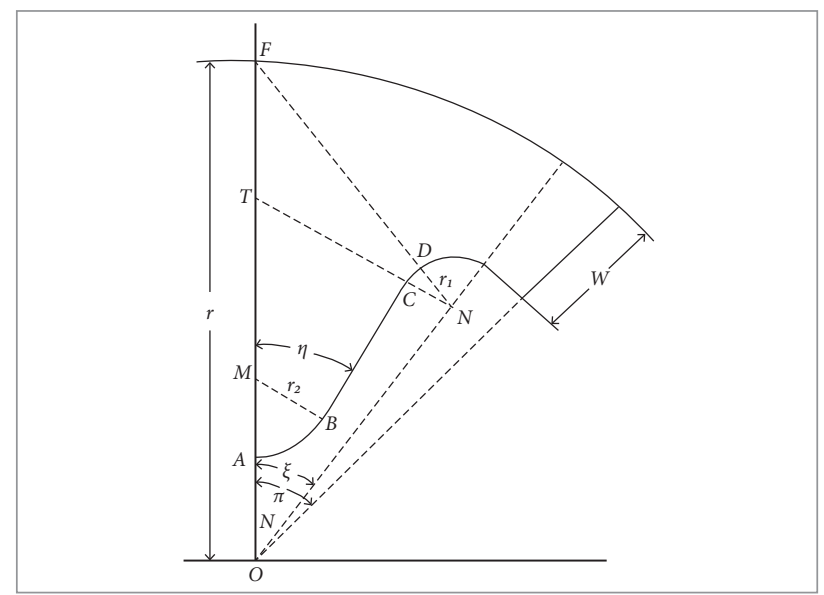

Figure 6. Star grain design variables. 
Grain radius and length specify combustion chamber length and radius, respectively. Thus, combustion chamber geometry is derived using Eq. 5:

$$
\begin{aligned}
& L_{c} \simeq 1.1 L_{\text {Grain }} \\
& R_{c}=R_{\text {Grain }}+\delta_{T P S}
\end{aligned}
$$

where: $L_{\text {Grain }}$ is the grain length; $L_{c}$ is the combustion chamber length; $R_{\text {Grain }}$ is the grain radius; $d_{T P S}$ is the required TPS thickness which will be derived in the next section.

The flow data of the grain discipline is illustrated in Fig. 7.

\begin{tabular}{|l|l|c|}
\hline$A_{\text {req burn }}, A_{\text {req port }}$ & $\begin{array}{c}\text { Grain design } \\
\text { and } \\
\text { Grain type }\end{array}$ & $A_{b}(w), A_{p}(w), L_{\text {Grain }}$ \\
$\begin{array}{c}\text { combustion } \\
\text { chamber } \\
\text { modeling }\end{array}$ & $V_{\text {Comb }}, V_{\text {Comb }}, R_{\text {Grain }}$ \\
& Grain geometry parameter \\
\end{tabular}

Figure 7. Grain design and input-output diagram.

\section{HEAT TRANSFER DISCIPLINES}

Heat transfer from combustion chamber and thermal modeling of solid propellant thrusters are among the important disciplines in propulsion design algorithm. Hard coupling between thermal limitation and thruster's performance (such as pressure, mass flow, etc.) takes place due the use of shared parameters in different disciplines (Adami 2015; Darabi et al. 2015). Analytical and computational tools were developed for over-cooled walls (Knab et al. 2009) but known computational and analytical methods are usually involved in CFD and longtime consumption. Such accuracy and time consumption are not needed for conceptual and preliminary design phase. Thus, engineering model can be useful to rapidly predict the heat flux. In this paper, rapid thermal modeling of combustion chamber is introduced, and thermal protection system mass with real combustion temperature is predicted.

The largest part of the heat is transferred from the hot chamber gases to the chamber walls by convection and radiation. The amount of heat transferred by conduction (gas) is small and usually negligible in preliminary design phases. In Adami (2015), it is shown that the best performance and minimum TPS mass are obtained by selection of 2 TPS layers. The first is ablative to control temperature, and the second is absorber to control heat flux. The thermal equilibrium of combustion chamber (internal-external burning) can be proposed as shown in Fig. 8.

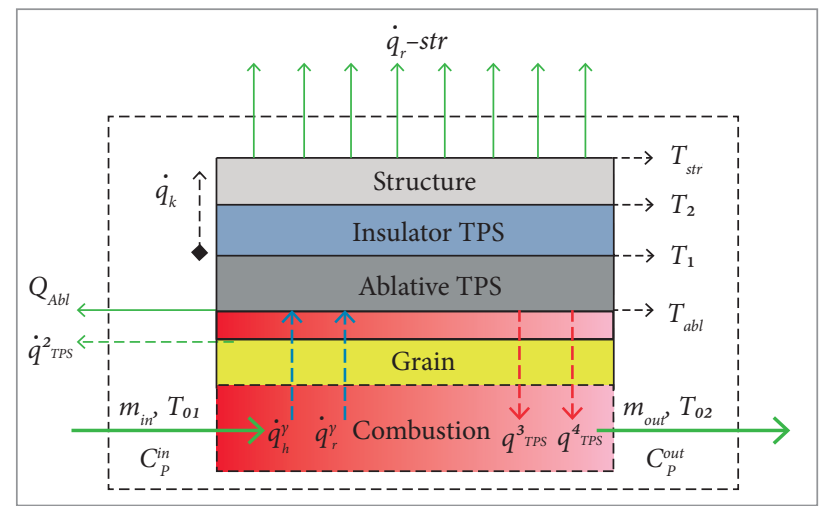

Figure 8. Thermal equilibrium of solid thruster with ablation and radiation.

In this model, it is considered that flow enters the control volume after combusting with adiabatic temperature $T_{01}$ :

$$
\dot{Q}_{\text {in }}=\dot{m}_{\text {propellant }} C_{P}^{\text {in }} T_{01}
$$

Combustion products lose energy by convection $\dot{q}_{h}^{\gamma}$ and radiation $\dot{q}_{r}^{\gamma}$.

$$
\begin{aligned}
& \dot{q}_{h}^{\gamma}=h_{\gamma}\left(\tilde{T}-T_{s}\right) \\
& \dot{q}_{r}^{\gamma}=\varepsilon_{\gamma} \sigma T_{01}^{4} \\
& \sigma=5.6697 \times 10^{-8} \frac{W}{\left(m^{2} \cdot K^{4}\right)} \\
& \tilde{T}=\frac{T_{01}+T_{02}}{2}
\end{aligned}
$$

where: $T_{s}$ is the inner TPS wall (ablative TPS) temperature; $\mathrm{T}$ the is mean temperature of the combustion chamber; $C_{P}{ }_{P}$ is the input specific heat coffecient at constant pressure; $T_{02}$ is a temperature of the combustion chamber after heat transferred (real temperature).

The prediction of convective heat coefficient $\left(h_{y}\right)$ is the most important part of thermal modeling of every combustion chamber. Sutton and Biblarz (2010) proposed Eq. 8 for prediction of $h_{y}$ and $\dot{q}_{r}^{\gamma}$.

$$
\begin{aligned}
& h_{\gamma}=\frac{k_{d}}{d} 0.0162 \operatorname{Pr}_{g}^{0.82} \operatorname{Re}_{g}^{0.82}\left(\frac{T_{a w}}{T_{w g}}\right)^{0.35} \\
& \dot{q}_{r}^{\gamma}=\dot{q}_{r}^{C_{2}}+\dot{q}_{r}^{H_{2} O}
\end{aligned}
$$


$\dot{q}_{r}^{\mathrm{CO}_{2}}=3.5 \sqrt[3]{P_{\mathrm{CO}_{2}} L_{e}}\left[\left(\frac{T_{a w}}{100}\right)^{0.35}-\left(\frac{T_{w g}}{100}\right)^{0.35}\right]$

$\dot{q}_{r}^{H_{2} O}=3.5 P_{\mathrm{CO}_{2}}^{0.8} L_{e}^{0.6}\left[\left(\frac{T_{a w}}{100}\right)^{3}-\left(\frac{T_{w g}}{100}\right)^{3}\right]$ $\dot{q}_{r}^{\gamma}$.

Huzel et al. (1992) proposed Eq. 9 for prediction of $h_{y}$ and

$h_{\gamma}=\left[\frac{0.026}{D_{t}^{0.2}}\left(\frac{\mu^{0.2} C_{P}}{\operatorname{Pr}^{0.6}}\right)\left(\frac{P_{0} g}{c^{*}}\right)^{0.8}\left(\frac{D_{t}}{R}\right)^{0.1}\right]\left(\frac{A_{t}}{A}\right)^{0.9} \sigma$

$\dot{q}_{r}^{\gamma} \sim 0$

Equations 8 and 9 need many inputs that are usually not available. Adami (2015) suggests Eq. 10, which is especially suitable for multidisciplinary design optimization:

$$
\begin{aligned}
& \varepsilon_{\gamma} \sim 0.1 \\
& h_{\gamma}=Z_{c} 0.5 \rho_{\text {comb }} V_{\text {flow }} C_{P} \mu^{0.3} \operatorname{Pr}^{-\frac{2}{3}}=Z_{c} \frac{\dot{m}_{\text {propellant }}}{2 A} C_{P} \mu^{0.3} \operatorname{Pr}^{-\frac{2}{3}} \\
& C_{P}=\frac{\gamma R}{\gamma-1}, \operatorname{Pr}=\frac{4 \gamma}{9 \gamma-1}, \mu=1.78 \times 10^{-7} M_{g}^{0.5} T_{01}^{0.6} \\
& Z_{c}=\frac{\pi R_{\text {Conb }}^{2}}{A_{\text {lat }}}
\end{aligned}
$$

where: $R$ is a constant parameter of gas combustion products; $g$ is an isentropic exponent; $P r$ is Prandtl number; $m$ is viscosity; $M_{g}$ is the molecular weight; $C_{P}$ is the specific heat at constant volume; $A$ is the cross section of the flow $\left(A^{*}<A<A_{\text {comb }}\right) ; A_{\text {lat }}$ is the lateral area; $Z_{c}$ is a correction factor that depends on combustion chamber geometry.

Input energy warms up the wall $\left(T_{s}\right)$, and the wall temperature approaches the maximum value called ablative temperature $\left(T_{A b l}\right)$. Ablative TPS begins to ablate, and the decomposition of ablative materials is complex, involving many and multifarious physical and chemical processes (Martin 2013). General relation of ablation is presented in Eq. 11:

$$
\dot{Q}_{A b l}=\dot{m}_{A b l} C_{A b l}=\dot{q}_{T P S}^{1} A_{l a t} \Rightarrow \dot{q}_{T P S}^{1}=\rho_{A b l} \dot{r}_{A b l} C_{A b l}
$$

where: $\rho_{A b l}$ is the ablative TPS density; $\dot{r}_{A b l}$ is the ablation velocity; $C_{A b l}$ is the ablation heat coefficient.

Some of the absorbed energy comes back to the combustion flow by radiation from hot wall and ablation mass flow at ablation temperature.

$$
\dot{q}_{T P S}^{3}=\dot{m}_{A b l} C_{P}^{A b l} T_{A b l} \quad \quad \dot{q}_{T P S}^{4}=\varepsilon_{A b l} \sigma T_{s}^{4}
$$

It should be noted that, if wall temperature is lower than ablative temperature, then ablation does not happen. Additionally, if inner burning grain such as star grain is considered, then hot gas does not touch the combustion chamber wall and ablation does not happen again. Input energy of ablation mass flow $\left(\dot{q}_{\text {TPS }}^{3}\right)$ absorbs some energy again until it reaches the real combustion chamber temperature and leaves the control volume.

$$
\dot{q}_{T P S}^{2}=\dot{m}_{A b l} C_{P}^{A b l}\left(T_{02}-T_{A b l}\right)
$$

Structure of chamber should be protected from high temperature. Ablative TPS keeps the inner wall temperature near constant but this temperature is high enough to melt any structure. Ablative materials have generally high density and high conductive heat coefficient $\left(K_{A b s}\right)$. It is not good to use ablative material as an insulator, therefore, a second TPS layer is proposed. Conductive heat from 2 TPS layers is finally emitted by radiation from lateral surface of structure.

$$
\begin{aligned}
& \dot{q}_{K}=K_{A b l} \frac{T_{A b l}-T_{1}}{\delta_{\text {Ablation }}(t)}=K_{\text {ins }} \frac{T_{1}-T_{2}}{\delta_{\text {Insulator }}} \\
& \dot{q}_{r-s t r}=\varepsilon_{s t r} \sigma T_{s t r}^{4}
\end{aligned}
$$

where: $d_{\text {Ablation }}$ and $d_{\text {Insulator }}$ are the ablative and insulator thickness, respectively.

Equation 14 are time-dependent, but critical condition can be rewritten as Eq. 15 for steady state condition.

$$
\begin{aligned}
& \dot{q}_{K}=K_{\text {ins }} \frac{T_{A b l}-T_{s t r}}{\delta_{\text {Insulator }}} \\
& \dot{q}_{r-s t r}=\varepsilon_{s t r} \sigma T_{s t r}^{4}
\end{aligned}
$$

Steady state condition and thermal equilibrium for propellant flow, TPS and total control volume lead to Eq. 16.

$$
\begin{gathered}
\dot{m}_{\text {propelant }} C_{P}^{i n} T_{01}+\dot{m}_{A b l} C_{P}^{A b l} T_{A b l}-A_{l a t} h_{\gamma}\left(\tilde{T}-T_{A b l}\right)- \\
-A_{l a t} \sigma\left(\varepsilon_{\gamma} T_{01}^{4}-\varepsilon_{A b l} T_{A b l}^{4}\right)=\left(\dot{m}_{A b l}+\dot{m}_{\text {propelant }}\right) C_{P}^{\text {out }} T_{02} \\
A_{\text {lat }} h_{\gamma}\left(\tilde{T}-T_{A b l}\right)+A_{\text {lat }} \sigma\left(\varepsilon_{\gamma} T_{01}^{4}-\varepsilon_{A b l} T_{A b l}^{4}\right)=\dot{m}_{A b l} C_{A b l}+A_{l a t} \varepsilon_{s t r} \sigma T_{s t r}^{4} \\
\varepsilon_{s t r} \sigma T_{s t r}^{4}=K_{\text {ins }} \frac{T_{A b l}-T_{s t r}}{\delta_{\text {Inssulator }}}
\end{gathered}
$$

These 3 equations have 4 unknowns including $T_{02}, \dot{m}_{\mathrm{Abl}}$ ' $T_{\text {str }}$, and $d_{\text {Insulator }}$. This condition is suitable for optimization. Objectives can be selected as minimizing $\dot{m}_{\mathrm{Abl}}$ or maximizing $T_{02}$, 
but unique answer will be derived from Eq. 16 if $T_{\text {str }}$ is known or specified. Finally, total TPS mass can be predicted by Eq. 17:

$$
\begin{aligned}
& M_{T P S}=M_{A b l}+M_{A b s} \\
& M_{A b l}=\dot{m}_{A b l} \Delta t \\
& M_{A b s}=\delta_{A b s} \rho_{A b s} A_{l a t}
\end{aligned}
$$

As mentioned before, if ablation is not needed, then Eq. 18 can be used alternatively. Unknowns are $T_{02}, d_{\text {Insulator }}$, and $T_{s}$.

$$
\begin{aligned}
& \dot{m}_{\text {propellant }} C_{P} T_{01}-A_{\text {lat }} h_{\gamma}\left(\tilde{T}-T_{s}\right)-A_{\text {lat }} \sigma\left(\varepsilon_{\gamma} T_{01}^{4}-\varepsilon_{A b l} T_{s}^{4}\right)=\dot{m}_{\text {propellant }} C_{P} T_{02} \\
& A_{\text {lat }} h_{\gamma}\left(\tilde{T}-T_{s}\right)+A_{\text {lat }} \sigma\left(\varepsilon_{\gamma} T_{01}^{4}-\varepsilon_{A b l} T_{s}^{4}\right)=A_{\text {lat }} \varepsilon_{s t r} \sigma T_{s t r}^{4} \\
& \varepsilon_{s t r} \sigma T_{s t r}^{4}=K_{\text {inrs }} \frac{T_{s}-T_{s t r}}{\delta_{\text {Insulator }}}
\end{aligned}
$$

\begin{tabular}{|c|c|c|}
\hline Nozzle geometry & \multirow{5}{*}{$\begin{array}{l}\text { Heat transfer } \\
\text { modeling }\end{array}$} & \multirow[b]{2}{*}{$\dot{q}_{h}, \dot{q}_{r}, \dot{q}_{k}, h_{c o}$} \\
\hline$\dot{m}, T_{\text {Adiabatiic }}, T_{s t r}, P C$ & & \\
\hline Combustion geometry & & $T_{s t r}, T_{a b p}, T_{I n s}$ \\
\hline TPS properties & & $\delta_{\text {Ablation, }}, \delta_{\text {Insulator }}$ \\
\hline Propellant properties & & $\mathrm{M}_{\mathrm{TPS}}, \mathrm{T}_{\mathrm{C}}$ \\
\hline
\end{tabular}

Internal burning grain does not need ablative TPS in combustion, but ablative material is needed for throat of the nozzle. Properties of some thermal protection materials are summarized in Table 1 (NASA 1968, 2015). Finally, flow data of the heat transfer discipline is illustrated in Fig. 9.

Figure 9. Heat transfer discipline and input-output diagram.

To rapidly model the heat transfer, it is proposed to select three sections including combustion chamber, convergent part of the nozzle, and divergent part of the nozzle. Thus, flow enters with adiabatic temperature and exits with total temperature $T_{02}$.
Convergent part of nozzle is designed based on $T_{02}$ including throat area. Flow enters the convergent part with $T_{02}$ and exits from throat with total temperature $T_{03}$. Divergent part of the nozzle is designed based on $T_{03}$ including exit area. Finally, flow enters the divergent part with $T_{03}$ and exits from the nozzle with total temperature $T_{c}$.

\section{MASS PREDICTION AND} CORRECTION FACTORS

Total thruster mass (combustion chamber, cap, TPS, propellant, and nozzle) is estimated from Eq. 19:

$$
\begin{aligned}
& M_{\text {Thruster }}=M_{\text {Cap }}+M_{\text {Nozzle }}+M_{\text {propellant }}+M_{\text {Comb }}+M_{\text {TPS }} \\
& M_{\text {Comb }}=\left(2 \pi R_{c} L_{c}+\pi R_{c}^{2}\right) \delta_{\text {Comb }} \rho_{\text {str }} \\
& M_{\text {Nozzle }}=\left[\frac{\pi}{\tan \theta_{1}}\left(R_{c}^{2}-R_{t}^{2}\right)+\frac{\pi}{\tan \theta_{2}}\left(R_{e}^{2}-R_{t}^{2}\right)\right] \delta_{\text {Nozzle }} \rho_{\text {str }} \\
& M_{\text {Cap }}=\left(2 \pi R_{c}^{2}\right) \delta_{\text {Comb }} \rho_{\text {str }} \\
& M_{\text {propellant }}=V_{\text {propellant }} \rho_{\text {propellant }} \\
& M_{\text {TPS }}=M_{A b l}+M_{\text {Abs }}
\end{aligned}
$$

\begin{tabular}{|c|c|c|c|c|c|}
\hline Material & $\begin{array}{c}K_{T P S} \\
(W / m K)\end{array}$ & $\begin{array}{c}\text { Cp } \\
\text { [J/kgK] }\end{array}$ & $\begin{array}{c}\rho \\
{[\mathrm{Kg} / \mathrm{m}]}\end{array}$ & $T_{A b l}$ & $\begin{array}{c}C_{A b)} \\
(\mathrm{MJ} / \mathrm{kg})\end{array}$ \\
\hline Silica & 1.3 & 740 & 320 & 1,685 & - \\
\hline Silicon carbide & 0.82 & 750 & 310 & 1,650 & - \\
\hline Alumina & 0.62 & 775 & 512 & 2,090 & - \\
\hline Zirconia & 0.14 & 700 & 736 & 2,480 & - \\
\hline Graphite & 1.59 & 1,631 & 1,400 & 3,778 & 66.8 \\
\hline Avcoat39-5026 & 25 & 1,110 & 513 & 835 & 47 \\
\hline
\end{tabular}

According to the selected configurations, cylindrical geometry is used for combustion chamber. Required thicknesses can be calculated using Eq. 20:

$$
\delta_{s y l}=n_{S . F} \frac{P_{i} R_{i}}{\sigma_{s t r}}
$$

where: $n_{S . F}$ is a safety factor and is taken close to 2 for space application.

Average thicknesses at combustion chamber section and end nozzle section is used for the nozzle.

Table 1. Summary of some TPS properties. 


$$
\begin{aligned}
& \delta_{\text {comb }}=n_{S . F} \frac{P_{C} R_{c}}{\sigma_{\text {str }}} \\
& \delta_{\text {nozzle }}=0.5 \frac{n_{S . F}}{\sigma_{\text {str }}}\left(P_{C} R_{c}+P_{e}\right.
\end{aligned}
$$

Flow data of mass modeling is illustrated in Fig. 10. Some correction factors are usually applied to compensate the effect of the model simplification and to adjust the results in comparison with real thrusters. Equation 22 presents the minimum required correction factors to modify the results:

$$
\begin{aligned}
& I s p_{\text {real }}=\lambda_{2} I s p_{\text {Ideal }} \\
& M_{\text {Total }}=n_{\sigma}\left(M_{\text {Cap }}+M_{\text {Nozzle }}+M_{\text {propellant }}+M_{\text {Comb }}+M_{\text {TPS }}\right)
\end{aligned}
$$

where: $\lambda_{2}$ is a temperature correction factor; $n_{s}$ is the mass

\begin{tabular}{|c|c|c|}
\hline$R C, L C, P C$ & \multirow{3}{*}{$\begin{array}{c}\text { Mass } \\
\text { modeling }\end{array}$} & \\
\hline \multirow{2}{*}{ MTPS, Mpropellant } & & MThruster \\
\hline & & \\
\hline
\end{tabular}
correction factor.

Values of the mentioned correction factors are adjusted during the validation.

Figure 10. Mass modeling.

\section{MULTIDISCIPLINARY DESIGN OPTIMIZATION ALGORITHM}

The optimization of complex engineering systems is an integral part of design. Originally, those that created aerospace vehicles were responsible for every aspect, from wing shape to propulsion. As the size of aerospace systems grew, however, the design of such enormously complex problems was broken down into disciplines concentrating only on part of the whole. Over the years, 2 main design approaches have persisted. First, designers try several alternate designs and use the fixed-point iteration (FPI) process to converge them (Hosseini et al. 2011). A global criterion is used to choose the best design, but, because no global optimization takes place, there is no guarantee that the global optimum is reached. This is the conventional method. Alternatively, multidisciplinary design optimization (MDO) technique simultaneously optimizes every discipline and finds a global optimum solution (Hosseini et al. 2011). Unfortunately, decoupling of disciplines has optimization penalty and low feasibility. Finding an optimum solution in shorter elapsed time needs a more efficient algorithm.

MDO techniques consist of single-level and multi-level methods such as all at once (AAO), collaborative optimization (CO), bi-level integrated system synthesis (BLISS), and concurrent subspace optimization (CSSO) (Adami et al. 2015a; Adami et al. 2015b). AAO is the most basic MDO technique and has wide industry acceptance. In AAO, control is given to a system-level optimizer that ensures a global objective is met by having a single designer control in the entire system. AAO solves the global MDO problem by moving all local-level design variables and constraints away from each discipline to a new system-level optimizer entrusted with optimizing a global objective. High feasibility in solution is one of the advantages of AAO, but increasing the design variable leads to long optimizing procedure (Adami et al. 2015a). $\mathrm{CO}$ is a 2-level MDO algorithm originally developed in 1996 by Braun (1996) and is expected to maintain expert control in each discipline as well as incorporate parallel execution by removing iteration loops, presenting a 2-level structure similar to industry organizational structures. To coordinate between disciplines, $\mathrm{CO}$ creates copies of all interdisciplinary coupling variables at the system-level. The system optimizer uses these copies to send out design targets to each discipline. Most disadvantages of CO are values convergence and low feasibility in solution because of more system constraints.

Solid propulsion system design including heat transfer is a complex problem, which has looped disciplines. For example, heat flow calculation needs thruster geometry while geometry depends on TPS thicknesses. Decoupling of such disciplines leads to increase in system-level optimization variables and decrease in feasibility. Thus, new approach of MDO is used, which has higher efficiency for hard coupling systems. In this framework, shared variables between disciplines are only selected as design variables and all the other design variable should be optimized in a subsystem-level. New subspaces are introduced by integrating concurrent connected disciplines. A copy of system-level cost function is created for internal disciplines optimization. It is clear that the minimum optimization of system-level variables is used with maximum feasibility.

Hybrid optimization methods use a combination of gradientbased and heuristic methods. An example of hybrid method is to use a heuristic method to move towards a global solution area, and switch to a second order gradient-based method to quickly move towards the final solution. Therefore, hybrid optimization methods utilize advantages of both gradient-based 
methods and heuristic methods by combining the speed of local optimization with the robustness of global optimization. GA and SQP are common pair of hybrid optimization methods and are applied in this paper as system-level optimizer. Internal disciplines optimization is done by SQP algorithm. Flow data of multidisciplinary design optimization of solid thruster is proposed in Fig. 11.

Colored disciplines have an internal optimization. As shown in Fig. 11, only 2 design variables $\left(P_{c}, \dot{m}\right)$ are needed for optimum design of solid propulsion system with specific thrust level and burning time. Minimum total mass will be derived by trading off between minimum propellant mass and minimum dry mass. Total mass $\left(M_{\text {Total }}\right)$ is considered as a cost function, which should be minimized. Total impulse $\left(I_{\text {Total }}=I_{\text {Total }}^{\text {req }}\right)$ is considered as a system equality constrains. Structure temperature $\left(T_{s t r} \leq T_{p e r}\right)$ and maximum permitted diameter $\left(D_{c}, D_{e} \leq D_{\text {max }}\right)$ are most important inequality constrains which are transferred to the subsystem level.

\section{VALIDATION}

Modeling of each part of the solid thruster should be complex enough to have an acceptable estimation of thruster mass, geometry, and performance. Results of the proposed algorithm could be converged to real solid thruster data by using some correction factors. Correction factors are adjusted during validation by comparing the results with over ten real thrusters. Properties of some real solid propulsion are summarized in Table 2. All of the solid propulsion stages use hydroxyl-terminated poly butadiene (HTPB).

Figure 12 shows the mass relation, and Fig. 13 shows the Isp relation between real thrusters and the proposed algorithm. According to the results, the values of correction factors are proposed as relations:

$$
\begin{aligned}
& \lambda_{2}=0.97 \text { Adiabatic Temp. Correction Factor } \\
& n_{s}=1.15 \text { Mass Correction Factor }
\end{aligned}
$$

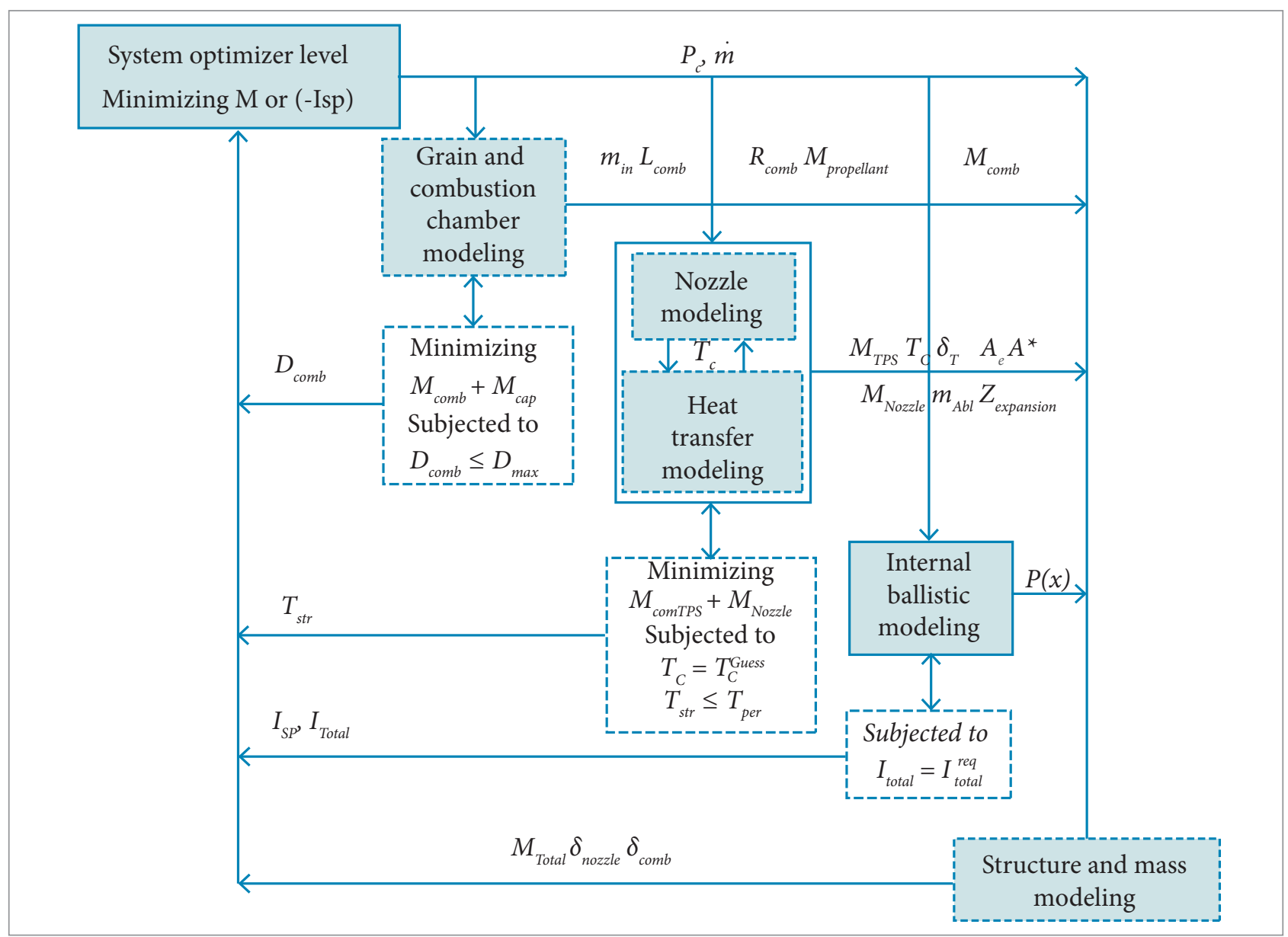

Figure 11. Flow data of multidisciplinary design optimization of solid thruster 
When the correction factors values are close to one, then, it can be said that modeling is accurate. By using the above value of the correction factor, the proposed results are equipped with experimental data. The worst case is related to third stage of Pegasus ${ }^{\circledR}$ launch vehicle. Comparison between the 3rd stage of Pegasus ${ }^{\circledR}$ launch vehicle and the proposed design algorithm is summarized in Table 3. It should be noted that this table shows the results before optimization. Average thrust $(32.6 \mathrm{KN})$, burning time (68.5 s), propellant (HTPB), pressure of combustion chamber (45.23 bar), expansion ratio (49.3) and grain geometry (star) are selected as inputs (Orbital 2010; ATK 2008).

Table 2. Real solid propulsion specifications.

\begin{tabular}{|c|c|c|c|c|c|c|c|c|}
\hline Solid propulsion & $\begin{array}{c}\text { Isp }_{v a c} \\
\text { [s] }\end{array}$ & $\begin{array}{l}\text { Length } \\
\text { [m] }\end{array}$ & $\begin{array}{c}\text { Diameter } \\
\text { [m] }\end{array}$ & $\begin{array}{c}\text { Dry mass } \\
\text { [kg] }\end{array}$ & $\begin{array}{l}\text { Propellant } \\
\text { mass [kg] }\end{array}$ & $\begin{array}{c}\text { Thrust }_{v a c} \\
\text { [ton] }\end{array}$ & $\begin{array}{l}\text { Burning } \\
\text { time [s] }\end{array}$ & $\begin{array}{l}\text { Expansion } \\
\text { ratio (area] }\end{array}$ \\
\hline Orion 38 (Pegasus $($ ) & 287 & 1.34 & 0.97 & 121 & 770 & 3.66 & 68.5 & 49.3 \\
\hline Orion 50SXL (Pegasus $®$ ) & 295 & 10.27 & 1.28 & 1,370 & 15,010 & 70.23 & 69.1 & 34.3 \\
\hline 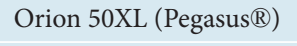 & 289 & 4.29 & 1.28 & 360 & 3,930 & 16.37 & 69.7 & 43.5 \\
\hline P80FW (Vega) & 279.5 & 11.71 & 3.0 & 7,330 & 88,365 & 310 & 109.8 & - \\
\hline Zefiro 23 (Vega) & 289 & 8.39 & 1.9 & 1,900 & 23,900 & 121.96 & 86.7 & - \\
\hline Zefiro 9A (Vega) & 294 & 3.85 & 1.9 & 780 & 10,115 & 31.92 & 128.6 & - \\
\hline SR-118 (Minotaur) & 282 & 8.39 & 2.34 & 3,620 & 45,370 & 226.8 & 56.4 & - \\
\hline SR-119 (Minotaur) & 309 & 7.88 & 2.34 & 3,180 & 24,490 & 124.7 & 60.7 & - \\
\hline Star 48VB (Minotaur) & 292.1 & 2.077 & 1.24 & 155 & 2,009 & $\sim 7$ & 84.1 & - \\
\hline Star 37FM (Minotaur) & 289.8 & 1.69 & 0.93 & 812 & 1,066 & 4.82 & 62.7 & - \\
\hline
\end{tabular}

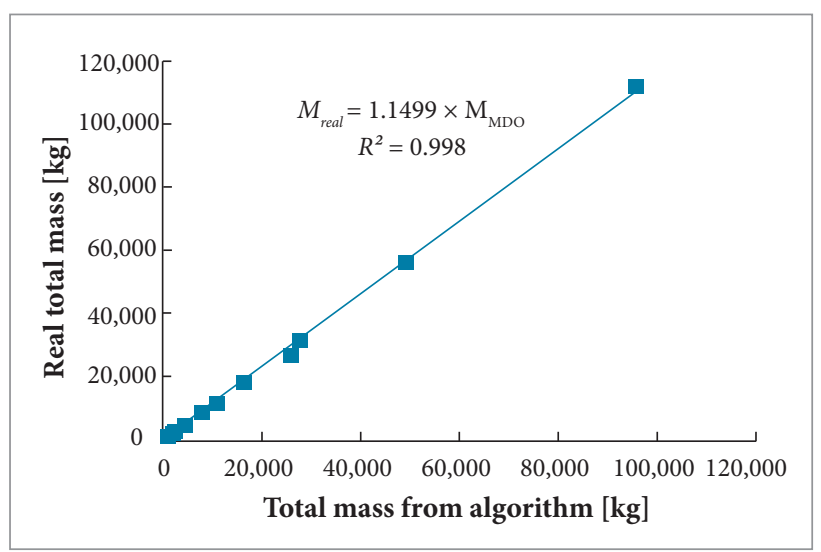

Figure 12. Comparison between real total mass and MDO result.

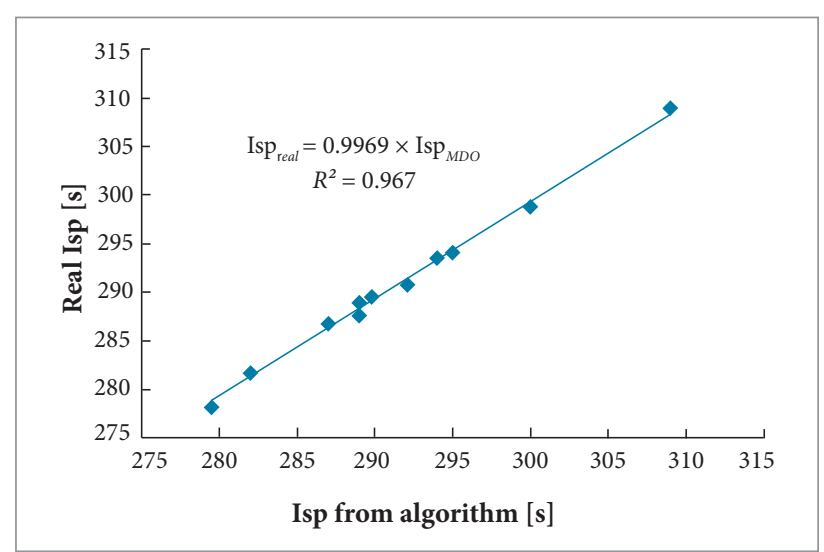

Figure 13. Comparison between real Isp and MDO result.

Table 3. Results comparison between real thrusters and the presented algorithm.

\begin{tabular}{|c|c|c|c|c|c|c|}
\hline & $\begin{array}{l}\text { Isp }_{v a c} \\
\text { [s] }\end{array}$ & $\begin{array}{l}\text { Length } \\
\text { [m] }\end{array}$ & $\begin{array}{l}\text { Diameter } \\
\text { [m] }\end{array}$ & $\begin{array}{l}\text { Exit diameter of the nozzle } \\
\qquad[\mathrm{m}]\end{array}$ & $\begin{array}{l}\text { Total mass } \\
{[(\mathrm{kg}]}\end{array}$ & $\begin{array}{l}\text { Propellant mass } \\
\text { [kg] }\end{array}$ \\
\hline Orion 38 & 287 & 1.35 & 0.97 & 0.53 & 891 & 770 \\
\hline $\begin{array}{l}\text { Proposed } \\
\text { algorithm }\end{array}$ & 289.2 & 1.32 & 0.96 & 0.49 & 864 & 789 \\
\hline Error & $0.8 \%$ & $2.2 \%$ & $1 \%$ & $7.5 \%$ & $3 \%$ & $2.5 \%$ \\
\hline Adiabatic method & 312.7 & 1.39 & 0.9 & 0.44 & 777 & 727 \\
\hline Error & $8.9 \%$ & $2.9 \%$ & $7.2 \%$ & $17 \%$ & $13 \%$ & $5.6 \%$ \\
\hline
\end{tabular}


According to the results of Table 3 , the proposed algorithm has acceptable accuracy in mass modeling (error $\leq 3 \%)$, thruster's dimensions estimation (error $\leq 7.5 \%$ ) and performance prediction (error $\leq 1 \%$ ). Such accuracy is suitable enough to be used in preliminary design phases. Errors become larger (near 17\%) if the heat transfer discipline is not considered.

\section{MULTIDISCIPUNARY DESIGN ANALYSIS OF SOLID PROPULSION SYSTEM}

Optimum length, diameter, expansion ratio, Isp, and operating pressure can be estimated using multidisciplinary design analysis. It means that optimum Isp value is not the maximum value and optimum dry mass is not the minimum value. For example, analysis of Orion-38 is done, and the results are presented as follows.

Because of constant mass flow, the combustion chamber pressure is the only optimization variable. According to the results of Fig. 14, increase in combustion chamber pressure leads to an increase in TPS mass and structure mass (dry mass) but a decrease in propellant mass. There is a minimum point for propellant mass that is related to variation of Isp. If heat transfer is not considered, then Isp increases with increase in combustion chamber pressure and propellant mass is decreased. Variation of total mass and Isp are illustrated in Fig. 15.

As shown in Fig. 15, optimum Isp and optimum total mass occur in different pressures of combustion chamber. Maximum Isp occurs in pressures near 70 bar, and the minimum total mass occurs in pressures near 30 bar. It should be noted that all of the above solid propulsion systems have a similar total impulse. The optimum configuration with maximum Isp is nearly $4 \%$ heavier than the optimum configuration with the minimum total mass. However, combustion chamber pressure of Orion-38 was selected as 45.23 bar.

\section{SUMMARY AND RESULTS}

In this paper, a new approach to multidisciplinary design optimization of a solid propulsion system has been introduced. The required disciplines have been considered including structure, aerothermodynamics, heat transfer, and grain geometry. Heat transfer from thruster was modeled and the governing equations of the combined ablative and radiative cooling were proposed. Adding the heat transfer discipline into the design procedure

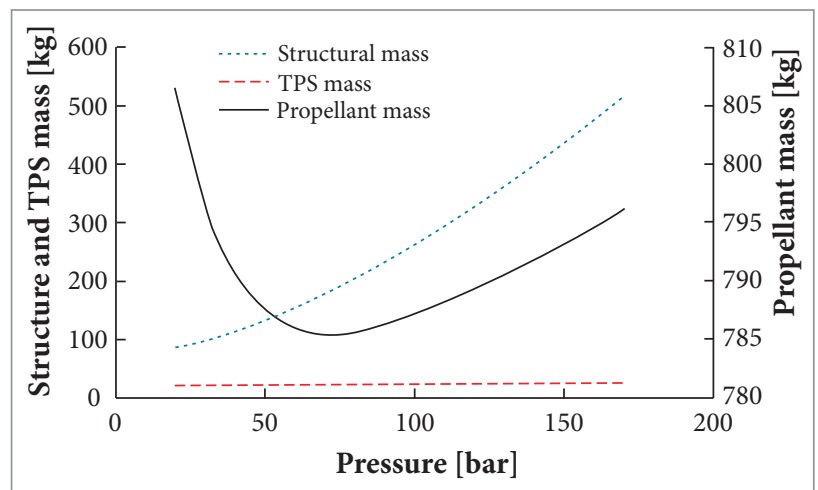

Figure 14. Variation of TPS mass, propellant mass, and structure mass.

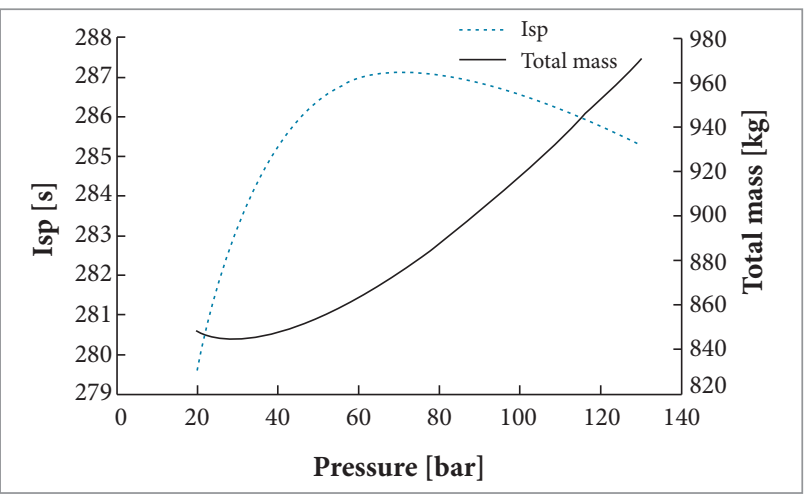

Figure 15. Variation of total mass and Isp.

increased difficulty and complexity due hard-coupled disciplines. To overcome this, a new MDO framework was introduced which is more efficient for such hard-coupled disciplines. The results of the proposed algorithm have been compared with more than ten operational solid propulsion systems. The derived correction factors are close to one with scattering level better than 0.97. According to the results, inclusion of heat transfer discipline in the model improved the accuracy of the numerical calculations. Maximum error was reduced from 17 to $8 \%$. As a case study, Orion 38 has been selected. By using MDO, the optimum configuration is directly derived including total length, combustion chamber diameter, expansion ratio, nozzle geometry, Isp, operating pressure, ablative TPS mass, and grain geometry.

\section{AUTHOR'S CONTRIBUTION}

Adami A developed the idea, Mortazavi M and Nosratollahi $\mathrm{M}$ prepared the case study. All the authors discussed the results and commented on the manuscript. 


\section{REFERENCES}

Acik S (2010) Internal ballistic design optimization of a solid rocket motor (Master's thesis). Ankara: Middle East Technical University.

Adami A (2015) Multidicsiplinary design optimization of Reentry Vehicle considering Guidance Algorithm (PhD thesis). Tehran: Amirkabir University of Technology.

Adami A, Mortazavi M, Nosratollahi M (2015a) Multi-modular design optimization and multidisciplinary design optimization. International Journal of Intelligent Unmanned Systems 3(2-3):156-170. doi: 10.1108/IJIUS-01-2015-0001

Adami A, Mortazavi M, Nosratollahi M, Taheri M, Sajadi J (2015b) Multidisciplinary design optimization and analysis of hydrazine monopropellant propulsion system. International Journal of Aerospace Engineering 2015:Article ID 295636. doi: 10.1155/2015/295636

Albarado K, Hartfield R, Hurston W, Jenkins R(2012) Solid rocket motor design using hybrid optimization, International Journal of Aerospace Engineering 2012:Article ID 987402. doi: 10.1155/2012/987402

ATK (2008) Alliant Techsystems Inc. Tactical Propulsion and Controls. 14 May 2008. Approved for Public Release OSR No. 08-S-0259 and OSR No. 08-S-1556. Dulles: ATK.

Braun RD (1996) Collaborative architecture for large-scale distributed design (PhD thesis]. Stanford: Stanford University.

Darabi H, Roshanian J, Zare H (2015) Design of liquid-propellant engine using collaborative optimization and evolutionary algorithms. Proc IME G J Aero Eng 229(2):232-242. doi: 10.1177/0954410014529423

Hainline RC (2006) Design optimization of solid rocket motor grains for internal ballistic performance (Master's thesis]. Orlando: University of Central Florida.

Hosseini M, Toloie A, Nosratollahi M, Adami A (2011) Multidisciplinary design optimization of an expendable launch vehicle. Proceedings of the International Conference on Recent Advances in Space Technologies; Istanbul, Turkey.

Huzel DK, Huang DH, Arbit H (1992) Modern engineering for design of liquid-propellant rocket engines. Washington: American Institute of Aeronautics and Astronautics.

Jodei J, Ebrahimi M, Roshanian J (2009) Multidisciplinary design optimization of a small solid propellant launch vehicle using system sensitivity analysis. Structural and Multidisciplinary Optimization

\section{8(1):93-100. doi: 10.1007/s00158-008-0260-5}

Knab O, Frey M, Görgen J, Maeding C, Quering K, Wiedmann D (2009) Progress in combustion and heat transfer modeling in rocket thrust chamber applied engineering. Proceedings of the 45th AIAA/ASME/ SAE/ASEE Joint Propulsion Conference \& Exhibit; Denver, USA.

Konečný P, Hrubý V, Křižan Z (2007) Design optimization of solid propellant rocket motor. Proceedings of the 23rd International Symposium on Ballistics; Tarragona, Spain.

Martin HT (2013) Assessment of the performance of ablative insulators under realistic solid rocket motor operating conditions (PhD thesis]. State College: Pennsylvania State University.

NASA (1968) NASA/SP-8009, Propellant slosh loads, NASA SPACE VEHICLE DESIGN CRITERIA (Structures), Washington: NASA.

NASA (2015) TPSX Update - Nov. 2015; [accessed 2016 Oct 29]. https://tpsx.arc.nasa.gov

Nisar K, Guozhu L (2008) A hybrid approach for design optimization of wagon wheel grain for SRM. AIAA 2008-4893.

Nisar K, Guozhu L, Zeeshan Q (2008) A hybrid optimization approach for SRM FINOCYL grain design Chin J Aeronaut 21(6):481-487. doi: 10.1016/S1000-9361(08)60164-8

Orbital (2010) Pegasus® user's guide. Release 7.0; [accessed 2016 Oct 29]. www.georing.biz/usefull/Pegasus_UG.pdf

Püskülcü G (2004) Analysis of 3-D grain burnback of solid propellant rocket motors and verification with rocket motor tests (Master's thesis]. Department of Mechanical Engineering; Ankara; Turkey.

Roshanian J, Keshavarz Z (2006) Multidisciplinary design optimization applied to a sounding rocket. J Indian Inst Sci 86(4):363-375.

Sutton GP, Biblarz O (2010) Rocket propulsion elements. 8th edition. Hoboken: John Wiley \& Sons.

Yildirim C (2007) Analysis of grain burnback and internal flow in solıd propellant rocket motors in 3 dımensıons (PhD thesis). Ankara: Middle East Technical University.

Zeeshan Q, Yunfeng D, Nisar K, Kamran A, Rafique A (2010) Multidisciplinary design and optimization of multistage ground-launched boost phase interceptor using hybrid search algorithm. Chin J Aeronaut 23(2):170-178. doi: 10.1016/S1000-9361(09)60201-6 